\title{
Clinical and epidemiological study of rectal cancer
}

\author{
Andrei Iulian Toader ${ }^{1,2}$, Calin Pavel Cobelschii,2, Aurel Mironescu ${ }^{1,3}$, \\ Alfred Redalf Alain Gheorghiu ${ }^{1,2}$, Adrian Maier ${ }^{2}$ \\ ${ }^{1}$ Faculty of Medicine, "Transilvania" University, Brasov, Romania \\ ${ }^{2}$ Surgery II Department, County Clinical Emergency Hospital, Brasov, Romania \\ ${ }^{3}$ Surgery Department, Clinical Children Hospital, Brasov, Romania
}

\begin{abstract}
Background. In this article, we present a study that tries to characterize the patient with rectal cancer who addresses the Brașov County Emergency Clinical Hospital (SCJUBv).

Aim. The aim of the study is to characterize from an epidemiological and clinical point of view the population group with rectal cancer that addresses the Brașov County Emergency Clinical Hospital, most of them being from Brașov County. We created a profile of the patient with rectal cancer in this area, outlining some risk factors. Material and methods. We conducted a prospective study of patients with rectal cancer hospitalized and operated in SCJUBv between 01.01.2013 and 31.12.2018. They were analyzed according to: age, sex, presence of associated diseases, symptoms at admission, presence of distant metastases, type of surgical treatment applied, local extension and histological type of the tumor.

Results. The studied group includes 79 patients hospitalized and operated at the Brașov County Emergency Clinical Hospital. Of these, 49 were men and 30 were women. The average age of the group is 67.76 years. Patients in the study group had multiple associated conditions. The first five places are occupied by the following diseases: hypertensive disorder, ischemic heart disease, anemia, dyslipidemia, type II diabetes. At hospital admission, the patients showed the following symptoms: rectorrhagia, intestinal transit disorders, weight loss, pain in the lower abdomen, perineal pain, loss of appetite, nausea and vomiting. Preoperative imaging examinations (ultrasound, CT) revealed secondary determinations located in the intra-abdominal lymph nodes, hepatic and pulmonary. Rectal amputation was performed in 67 cases and anterior rectal resection with anastomosis in 12 of the cases. The analysis of the histopathological examination bulletins allowed the quantification of the local extension of the tumor.

Conclusions. Based on this epidemiological and clinical study, we can draw the "robot portrait" of the patient with rectal cancer hospitalized in SCJU Brașov: is a 67-68 year old male, also presenting cardiovascular diseases with doctor appointment for rectal bleeding and intestinal transit disorders. Surgery will be performed with an amputation of the rectum. The histopathological diagnosis will be $\mathrm{G} 2$ adenocarcinoma in most cases.
\end{abstract}

Keywords: rectal cancer, epidemiology, clinic

\section{INTRODUCTION}

Malignant diseases are a major public health problem due to associated morbidity and mortality and due to the fact that they require special health policies for prevention, control and intervention $[1,2]$.

In the world, colorectal cancer ranks fourth in frequency and fourth in mortality, after bronchopulmonary cancer, breast cancer and liver cancer. The incidence rate of colorectal cancer has the highest value in Australia and New Zealand and lowest in West Africa. However, the highest mortality is recorded in Central and Eastern Europe $[1,3]$.

In Romania, colorectal cancer is the third leading cause of death. Along with other counties (Constanța, Iași, Sibiu), after 1990, Brașov County attracts attention with a significant increase in the number of patients with colorectal cancer. This is mainly explained by the increase in access to med- 
ical services rather than by changes in the environment or population behavior $[1,3]$.

The factors that condition the appearance of colorectal cancer are: genetic and biological factors, physical and social environmental factors, lifestyle and quality of health services. These factors have been studied to improve measures for the prevention, control and treatment of the disease [1].

The incidence of colorectal cancer is higher in men $[1,4]$.

The maximum incidence is in the sixth decade of life. After 45 years, the incidence doubles with every decade. Recent studies show an increase in the incidence of colorectal cancer in the young population under 50 years of age and particularly in individuals between 30 and 39 years of age [1,3,5-7].

Colorectal cancer is more common in urban than in rural areas, as well as in countries with medium or high living standards [1,5].

The relationship between diet and colorectal cancer has been extensively studied. Diet and lifestyle are thought to be responsible for about $90 \%$ of colorectal cancers.

The remaining $10 \%$ are genetically determined. The low incidence of colorectal cancer has been associated with consumption of: fiber, vegetables, seeds, folate rich aliments, coffee, NSAIDs, hormone replacement therapy. A favorable role in the occurrence of colorectal cancer is attributed to: fat consumption, red meat, cholesterol, smoking, alcohol consumption (especially beer). The use of a proinflammatory diet (rich in saturated fatty acids and cholesterol) is associated with an increased risk of colorectal cancer, especially colon cancer in men. Adopting a mediterranean diet decreases this risk $[1,4,8]$.

Visceral obesity, illustrated by waist circumference, is a risk factor for colorectal cancer, especially in men.

The increase in physical activity is correlated with a decrease in the risk of chronic diseases: cardiovascular, diabetes, and also colorectal cancer $[9,10]$.

Smoking and alcohol consumption are underestimated risk factors. Avoiding these toxins may partially explain the low frequency of colorectal cancer in mormons and 7 th-day adventists $[1,4,11]$.

Bariatric surgery may increase the risk of colorectal cancer, but further studies are needed [12].

Starting from the data from the literature, table 1 presents the factors that influence the incidence of colorectal cancer.
TABLE 1. Factors that influence the incidence of colorectal cancer

\begin{tabular}{|c|c|c|}
\hline & $\begin{array}{l}\text { POSITIVE FACTORS } \\
\text { (associated with low } \\
\text { incidence of colorectal } \\
\text { cancer) }\end{array}$ & $\begin{array}{l}\text { NEGATIVE FACTORS } \\
\text { (associated with } \\
\text { increased incidence of } \\
\text { colorectal cancer) }\end{array}$ \\
\hline $\begin{array}{l}\text { Diet and } \\
\text { lifestyle }\end{array}$ & $\begin{array}{l}\text { - Vegetable fibers } \\
\text { - Seeds } \\
\text { - folate } \\
\text { - Coffee } \\
\text { - Physical activity }\end{array}$ & $\begin{array}{l}\text { - Vegetable fats } \\
\text { - Red meat } \\
\text { - Cholesterol } \\
\text { - Biliary steroids } \\
\text { - Alcohol (drink) } \\
\text { - Inactivity } \\
\text { - Smoking }\end{array}$ \\
\hline $\begin{array}{l}\text { Drugs and } \\
\text { pathological } \\
\text { history }\end{array}$ & $\begin{array}{l}\text { - } \text { Aspirin } \\
\text { - } \text { Hormone } \\
\text { substitutes } \\
\text { - } \text { NSAIDs } \\
\text { - } \text { Calcium } \\
\text { - Vitamins: A, C, E, } \\
\text { beta-carotene }\end{array}$ & $\begin{array}{l}\text { - Cholecystectomy } \\
\text { - Vagotomy } \\
\text { - Pelvic radiotherapy } \\
\text { (especially in } \\
\text { women) } \\
\text { - Bariatric surgery }\end{array}$ \\
\hline $\begin{array}{l}\text { Genetic } \\
\text { factors }\end{array}$ & - Female gender & $\begin{array}{l}\text { - Male gender } \\
\text { - Familial } \\
\text { adenomatous } \\
\text { polypomatosis } \\
\text { - Lynch type I and II } \\
\text { non-polyposis cancer } \\
\text { - } \text { Muir-Torre syndrome }\end{array}$ \\
\hline $\begin{array}{l}\text { Environmental } \\
\text { and social } \\
\text { factors }\end{array}$ & $\begin{array}{l}\text { - } \text { Rural } \\
\text { - } \text { Mormons } \\
\text { - Seventh-day } \\
\\
\text { adventists }\end{array}$ & $\begin{array}{l}\text { - Urban } \\
\text { - Increased socio- } \\
\text { economic stress }\end{array}$ \\
\hline
\end{tabular}

The symptoms of rectal cancer are mainly rectorage and mucus elimination. Dorsal, sacred, perineal pain appears late in evolution, being explained by a degree of local advancement [13].

\section{AIM}

The aim of the study is to characterize from an epidemiological and clinical point of view the population group with rectal cancer that addresses the Brașov County Emergency Clinical Hospital, most of them being from Brașov County. We created a profile of the patient with rectal cancer in this area, outlining some risk factors.

\section{MATERIAL AND METHODS}

We conducted a prospective study of patients with rectal cancer hospitalized and operated in SCJUBv between 01.01.2013 and 31.12.2018. The studied group includes 79 patients. They were analyzed according to: age, sex, presence of associated diseases, symptoms at admission, presence of distant metastases, type of surgical treatment applied, local extension and histological type of the tumor. The socio-economic impact on the health system was analyzed based on the number of days of hospitalization. 
Data were collected from observation sheets, surgical protocols and histopathological analysis bulletins.

\section{RESULTS}

The studied group includes 79 patients hospitalized and operated at the Brasov County Emergency Clinical Hospital between 01.01.2013 and 31.12.2018.

Of these, 49 were men $(62.03 \%)$ and 30 were women (37.97\%). The oldest patient was 83 years old, and the youngest 43 years.

The average age of the group is 67.76 years. For men, the maximum age was 82 years, the minimum age was 50 years, and the average age was 68.36 years. For women, the maximum age was 83 years, the minimum age was 43 years, and the average age was 68.60 years.

The elderly, patients over 70 years, represent $51.89 \%$ (41 patients over 70 years). The distribution of the elderly by sex is as follows: $51.02 \%$ of men (25 patients) and $53.33 \%$ of women (16 patients).

Patients in the study group, in addition to rectal cancer, had multiple associated conditions. The first five places are occupied by the following diseases: hypertensive disorder (47 patients, 59.49\%), ischemic heart disease (30 patients, $37.97 \%$ ), anemia (21 patients, $26.58 \%$ ), dyslipidemia (17 patients, $21.52 \%$ ), type II diabetes (12 patients, $15.19 \%$ ).

The associated digestive disorders were represented by: gallstones ( 4 cases), gastroduodenal ulcer, diverticular disease of the colon, colonic polyps (two cases each).

At hospital admission, the patients showed the following symptoms (in order of frequency): rectorrhagia (44 cases, $55.69 \%$ ), intestinal transit disorders (30 cases, $37.97 \%$ ), weight loss (16 cases, $20.25 \%$ ), pain in the lower abdomen (13 cases, $16.46 \%$ ), perineal pain (12 cases, $15.19 \%$ ), loss of appetite, nausea and vomiting ( 9 cases, $11.39 \%$ ).

Preoperative imaging examinations (ultrasound, CT) revealed secondary determinations located in the intra-abdominal lymph nodes (7 cases), hepatic ( 5 cases) and pulmonary ( 3 cases).

All patients received surgical treatment. Rectal amputation was performed in 67 cases $(84.81 \%)$ and anterior rectal resection with anastomosis in 12 of the cases $(15.19 \%)$.

The analysis of the histopathological examination bulletins allowed the quantification of the local extension of the tumor. This analysis was per- formed on a subgroup of 75 patients and the TNM staging of tumors was used as a reference [13].

The results were as follows:

- T1 - submucosal invasion - 3 cases (4\%)

- T2 - invasion of muscularis propria - 25 cases $(33.33 \%)$

- T3 - invasion of the subserosal and perirectal tissue of the subperitoneal rectum -40 cases $(53.33 \%)$

- T4 - invasion of neighboring organs -7 cases $(9.33 \%)$.

- From a histological point of view, the following were identified: adenocarcinoma in 77 cases, (97.47\%), squamous cell carcinoma in 1 case and mucosecretory carcinoma in 1 case.

- The degree of differentiation of the tumor had the following distribution:

- G1 - well-differentiated tumors - 2 cases $(2.53 \%)$

- G2 - moderately differentiated tumors -71 cases $(89.87 \%)$

- G3 - poorly differentiated tumors - 6 cases (7.59\%).

For the patients in the study group, the total number of hospitalization days was 1,449 (3.98 years), with an average of 19.32 days per patient. The maximum hospitalization duration was 65 days, and the minimum 4 days.

\section{DISCUSSION}

Rectal cancer is a major public health problem due to high frequency, morbidity and associated mortality $[1,2]$.

Prevention of this disease is a permanent challenge for the medical world, illustrated by multiple epidemiological and clinical studies to identify risk factors.

Our group study includes 79 patients. Men are more affected by this disease, as illustrated by the higher percentage of patients $(62.03 \%$ men vs. $37.97 \%$ women). These results are consistent with other studies $[1,4]$.

The average age in the studied group is almost 68 years, significantly equal for both sexes and higher than other data in the literature: 63 years for men and 62 years for women [1].

There is an increased percentage of the elderly (patients over 70 years) in the study group $(51.89 \%)$, without gender differences $(51.02 \%$ men over 70 years): $53.33 \%$ women over 70 years. Because this category of patients is prone to postoperative complications, it requires increased at- 
tention preoperatively, during surgery and in postoperative care [14].

In addition to the advanced age of the studied group, we identified the presence of numerous associated diseases. Cardiovascular diseases are by far the most common: hypertension (47 cases), ischemic cardiac disease (30 cases), chronic heart failure (80 cases), mitral regurgitation (11 cases), tricuspid regurgitation (6 cases), aortic stenosis (4 cases), ACOMI (3 cases), aortic insufficiency and atrial fibrillation ( 2 cases each). These are followed by metabolic diseases: dyslipidemia (17 cases), type II diabetes (12 cases). Although these results may represent a reflection of the increased incidence of these diseases in the general population, their presence in patients with rectal cancer increases postoperative morbidity and mortality $[3,14]$.

Concomitant digestive disorders are poorly represented in the studied group. Hemorrhoidal disease ( 5 cases, $6.32 \%$ ) may be secondary to rectal tumor rather than a separate condition. Both gallstones (due to alteration of metabolism of bile salts and change of the colonic microbial flora) and colonic polyps (because the relationship between adenomatous polyps and cancer is well known) are risk factors for colon cancer $[4,13]$.

On the studied group there is a reduced association of these diseases with rectal cancer: gallstones -4 cases $(5.06 \%)$ and colonic polyps -2 cases $(2.53 \%)$. This suggests a lesser involvement of these diseases in the pathology of rectal cancer.

The symptoms present at hospitalization are dominated by: rectorrhage (more than half of the cases), followed by intestinal transit disorders and weight loss. Rectorrhage, intestinal transit disorders and perineal pain are suggestive for rectal conditions and require rectal examination. Thus, the anal canal, the lower and middle ampullary rectum (6-8 $\mathrm{cm}$ from the external anal orifice) are examined [13].

Weight loss, loss of appetite, nausea and vomiting are nonspecific symptoms and may be part of neoplastic impregnation syndrome [15].

Preoperative imaging examinations revealed metastatic disease in a few cases, the preferred site being the intra-abdominal lymph nodes.

Surgical treatment is dominated by abdominal-pelvic rectal amputation (67 cases - 84.81\%).

The general status of the patient, the loco-regional situation (imaged preoperatively, but also intraoperatively) and the surgical team have an important role in choosing the operative techniques.

Rectal amputation means permanent colostomy and a postoperative perineal wound (which requires special attention), therefore an increase in morbidity and a possible alteration in the quality of life [16].

From the point of view of local extension, the T3 stage was encountered in more than half of the cases $(53.33 \%)$.

Consistent with data from the scientific literature, the histopathological type of tumors removed was adenocarcinoma in almost all cases ( 77 cases). It had, in almost $90 \%$ of cases, a moderate degree of differentiation (G2-89.87\%).

The average hospitalization per patient in the study group was 19.32 days. Long hospital stay is an important indicator of economic impact. The causes can be multiple: preoperative investigations and interdisciplinary consultations performed during hospitalization, the high percentage of rectal amputations with the need for postoperative perineal wound care for a longer time [16].

The results presented following the analysis of the studied group may be influenced by the limits of the study: small number of patients and short period of postoperative follow-up (hospitalization period and period of follow-up of perineal wound).

\section{CONCLUSIONS}

Finally, based on this epidemiological and clinical study, we can draw the "robot portrait" of the patient with rectal cancer hospitalized in SCJU Brasov. This patient is a 67-68 year old male, also presenting cardiovascular diseases (mainly hypertension and ischemic cardiac disease), with doctor appointment for rectal bleeding and intestinal transit disorders. After having established the diagnosis, surgery will be performed with an amputation of the rectum. The histopathological diagnosis will be $\mathrm{G} 2$ adenocarcinoma in most cases. The patient will be discharged after approximately 20 days of hospitalization, being referred to the oncology service. We note with concern that over $50 \%$ of patients are older than 70 years.

Consistent with other authors, we advocate for the creation of strategies for the prevention of rectal cancer with diagnosis of the disease in less advanced stages and at younger ages. This would lead to a decrease in morbidity and mortality, as well as to a reduction in hospitalization days. Increasing the percentage of anterior rectal resections with anastomosis would have the same result.

We recommend extending the epidemiological and clinical study of rectal cancer to larger groups of patients in order to identify the characteristics of this population group, improve diagnostic, treatment methods and therapeutic outcomes, so that quality of life is increased. 


\section{REFERENCES}

1. Costea R. Aspecte clinice si epidemiologice în cancerul de rect. Editura Universitară „Carol Davila“, București, 2007.

2. Scripcariu V. Past, Present and Future in Colorectal Surgery. Chirurgia (Bucharest). 2019;114(2):147-151.

3. Agache A, Mustățea P, Mihalache $\mathrm{O}$ et al. Diabetes Mellitus as a Risk-factor for Colorectal Cancer Literature Review - Current Situation and Future Perspectives. Chirurgia (Bucharest). 2018; 113(5):603-610.

4. Andronescu PD. Tumorile rectale benigne și maligne. In: Tratat de patologie chirurgicală, vol. II, Angelescu N (ed.). Editura Medicală, București, 2001;1708-1727.

5. Loomans-Kropp HA, Umar A. Increasing Incidence of Colorectal Cancer in Young Adults. J Cancer Epidemiol. 2019;2019:9841295.

6. Syed AR, Thakkar P, Horne ZD et al. Old vs new: Risk factors predicting early onset colorectal cancer. World Journal of Gastrointestinal Oncology. 2019;11(11):1011-1020.

7. Wong MC, Huang J, Lok V et al. Differences in Incidence and Mortality Trends of Colorectal Cancer, Worldwide, Based on Sex, Age, and Anatomic Location. Clin Gastroenterol Hepatol. 2020.

8. Jakszyn $P$, Cayssials $V$, Buckland $G$ et al. Inflamatory potential of the diet and risk of colorectal cancer in the European Perspective Investigation into Cancer and Nutrition study. Int J Cancer. 2020.

9. Andreasson A, Hagstrom $\mathrm{H}$, Skoldberg $\mathrm{F}$ et al. The prediction of colorectal cancer using anthropometric measures: A Swedish population-based cohort study with 22 years of follow-up. United European Gastroenterol J. 2019;7(9):1250-1260.
10. Hillreiner A, Baumeister SE, Sedlmeier AM, Finger JD, Schlitt HJ, Leitzmann MF. Association between cardiorespiratory fitness and colorectal cancer in the UK Biobank. Eur J Epidemiol. 2020; 35(10):961-973.

11. Bendinelli B, Palli D, Assedi M, Facchini L, Grioni S, Agnoli C, Ricceri F et al. Alcohol, smoking and rectal cancer risk in a Mediterranean cohort of adults: the European Prospective Investigation into Cancer and Nutrition (EPIC)-Italy cohort. Eur J Gastroenterol Hepatol. 2020; 32(4):475-483.

12. Tao W, Artama M, von Euler-Chelpin M, Hull M, Ljung R, Lynge E et al. Colon and rectal cancer risk after bariatric surgery in a multicountry Nordic cohort study. Int J Cancer. 2020;147(3):728-735.

13. Dragomir C, Scripcariu V, Dajbog E. Cancerul de rect. In Tratat de chirurgie, vol. IX partea a II-a Chirurgie generală, Popescu I (ed.). Ed. Academiei Române, București, 2009;269-282.

14. Etele ÉE, Sala D, Dénes M, Cozlea A, Darie R, Török Á. Elderly Patients with Colorectal Cancer - A Predisposed Category for Postoperative Complications. Chirurgia (Bucureşti). 2019; 114(3):331-342.

15. Boloșiu HD. Semiologie medicală. Editura Medex, Cluj-Napoca, 1997; pp. 302-303.

16. Toader I, Cobelschi C, Mironescu A et al. Management of perineal wound post rectal amputation. Bulletin of the Transilvania University of Braşov. Series VI: Medical Sciences. 2017;10(2).

Conflict of interest: none declared Financial support: none declared 